\title{
DIAGNÓSTICO DE UMA USINA DE ASFALTO: SUBSÍDIOS À AVALIAÇÃO DE IMPACTOS AMBIENTAIS ATRAVÉS DO LEVANTAMENTO HISTÓRICO E DO MAPEAMENTO DE RISCOS ${ }^{1}$
}

\author{
DIAGNOSIS OF AN ASPHALT PLANT: SUBSIDIES TO THE ENVIRONMENTAL \\ IMPACT ASSESSMENT THROUGH THE ANALYSIS OF THE HISTORIC OF \\ NEGATIVE IMPACTS AND RISK MAPPING
}

\author{
Fábio Maciel Pinto ${ }^{2}$ e Carla Jane Weber ${ }^{3}$
}

\section{RESUMO}

Usinas de Concreto Asfáltico, são empreendimentos industriais destinados à produção de misturas asfálticas para aplicação em pavimentação. No contexto ambiental, são consideradas potencialmente poluidoras, pois podem promover alterações negativas no meio socioambiental. Assim, para a instalação desses empreendimentos, demanda-se a elaboração de diagnósticos técnicos interdisciplinares de fundo ambiental, minimamente abrangendo a caracterização dos aspectos físicos, bióticos e sociais do meio socioambiental que será afetado pelo empreendimento projetado. Tais diagnósticos servem como base para a elaboração da Avaliação de Impactos Ambientais. Esta analisará os dados apresentados nos diagnósticos, preverá os impactos ambientais negativos e positivos, determinará a importância, magnitude e abrangência dos impactos, e estabelecerá indicadores de qualidade, medidas mitigadoras, de controle e compensação socioambiental para o empreendimento. Entretanto, a avaliação poderá ser substancialmente enriquecida através da aplicação de métodos de análise do histórico de empreendimentos correlacionáveis, como de fluxogramas de beneficiamento, croquis e plantas de unidades, além do histórico comprovável de impactos ambientais. Nesse contexto, o trabalho analisou uma Unidade de Produção de Concreto Asfáltico com histórico de impactos ambientais negativos. A unidade operou no município de Joinville/SC, tendo gerado impactos duradouros associados a derramamentos de hidrocarbonetos, remediados após o encerramento das operações. Através da análise, foi possível identificar as instalações que originaram os impactos e elaborar mapa de riscos, o qual delimitou a Área de Emergência de Impactos, correspondente às instalações problemáticas, e a Área de Riscos de Acidentes Ambientais Graves, correspondente a área que será, preferencialmente, atingida por acidentes de cunho ambiental.

Palavras-Chave: Avaliação de Impactos Ambientais; Concreto Asfáltico; Usina de Asfalto.

\section{ABSTRACT}

An Asphalt Plant is an industrial facility for the manufacturing of asphalt mixtures for paving applications. That kind of industrial plant can cause harmful effects on the environment. Thus, projects evolving Asphalt Plants, requires interdisciplinary and technical evaluations of the environment. These evaluations should characterize aspects of the physical, biological and social environments that could be affected by the facility. Moreover, are needed for the Environmental Impact Assessment, that indicates the environmental consequences of the project and determines the importance, magnitude and scope of the harmful effects on the environmental. However, the Environmental Impact Assessment can be complemented with historical information about harmful environmental situations occurred in comparable projects. In this context, the paper analyzed an Asphalt Plant

1 Estudo de caso realizado para a determinação da origem das contaminações de solos e água, associadas a uma área contaminada.

2 Geólogo (UFPR). Especialista em Política e Economia Mineral (UFPA). Especialista em Perícia e Auditoria Ambiental (UNINTER). Programa de Pós-graduação em Clima e Meio Ambiente (IFSC). Email: fabiomacielpinto@gmail.com 3 Bióloga (UNIVALI-SC). Programa de Pós-graduação em Tecnologia e Meio Ambiente (IFC). Email: carlajaneweber@, gmail.com 
with historical of negative environmental impacts. The plant operated between 1974 and 2002, in the city of Joinville, Brazil, having generated impacts associated with oil spills, remedied after the closure of the plant. Through the study, it was possible to identify the industrial installations that originated the impacts and was possible to elaborate a risk map, which delimited the Emergency Impact Area, corresponding to the industrial installations that generated the harmful situations, and the Environmental Accident Risk Area, corresponding to the area that can be, preferably, affected by environmental accidents.

Keywords: Environmental Impact Assessment; Asphalt Concrete; Asphalt Mixing Plant.

\section{INTRODUÇÃO}

A Avaliação de Impactos Ambientais (AIA) é um estudo baseado em diagnósticos técnicos interdisciplinares, sociais e ambientais, que reúne informações e análises que possibilitam a determinação da viabilidade socioambiental de um empreendimento (Maciel-Pinto, 2020a). Os diagnósticos podem incluir aspectos locais e regionais do meio biótico, como fauna, flora, inventário ou censo florestal da área afetada, identificação e delimitação de unidades de conservação e áreas de preservação permanente; aspectos do meio social, como interferência em áreas indígenas e quilombolas, além de caracterizações econômicas, históricas, arqueológicas, culturais e sociais da área afetada; e aspectos do meio físico, como caracterização e identificação de possíveis interferências nos regimes hidrológicos, pedológicos, geológicos e da atmosfera, a identificação de padrões do background natural da área afetada e de padrões de distribuição ou concentração de contaminantes. Para tanto, a AIA abrange, lato sensu, as seguintes etapas:

a) previsão de impactos negativos e positivos, embasada nos diagnósticos e apoiada em informações adicionais, oriundas de modelagens, ensaios em ambiente controlado, histórico de acidentes ambientais, etc;

b) avaliação efetiva, com determinação da importância, magnitude e abrangência dos impactos;

c) estabelecimento dos indicadores de qualidade, medidas mitigadoras, de controle e compensação socioambiental.

Através dessa avaliação, a comunidade técnico-científica, representada pelos órgãos de licenciamento ambiental, promove a aprovação, solicita adequações, ou rejeita projetos de empreendimentos potencialmente poluidores, inclusive contando com a participação da sociedade, representada pela comunidade atingida e entidades com cunho social, jurídico, científico ou técnico (Santiago et al. 2015). Assim, a AIA promove o debate sobre as consequências das atividades antrópicas e incentiva a organização da sociedade, incluindo-a no processo de aprovação de projetos potencialmente poluidores (Santiago et al. 2015).

Depreende-se que a AIA é embasada em informações extraídas dos diagnósticos e visa elucidar as alterações socioambientais oriundas da intervenção antrópica. Além disso, indica medidas mínimas para a promoção do direito ao meio ambiente equilibrado e promove o debate público sobre os projetos potencialmente poluidores abrangidos no seu escopo. 
Entretanto, deficiências não são exceções, sendo que avaliações deficitárias podem culminar em situações ambientalmente e socialmente graves (Maciel-Pinto, 2020a). Inclusive, por mais elaborados e bem conduzidos que sejam os diagnósticos e os processos decisórios de licenciamento ambiental, de nada valerá o esforço se a AIA não for seriamente executada (Sandoval \& Cerri, 2009).

Métodos como o mapeamento de processos, através da análise de fluxogramas, croquis e plantas industriais; análise do histórico de eventos poluidores em empreendimentos correlacionáveis; e o mapeamento de riscos de acidentes ambientais, podem enriquecer sobremaneira a AIA, minimizando deficiências na identificação e classificação dos impactos ambientais prováveis (Maciel-Pinto, 2020a). Dentre essas possibilidades de enriquecimento da AIA, o estudo do histórico de empreendimentos semelhantes ou correlacionáveis, pode ser fundamental para a previsão de locais e situações vulneráveis à ocorrência de impactos socioambientais negativos (Maciel-Pinto, 2020a). Nesse contexto, o presente trabalho relaciona informações básicas sobre uma Unidade de Produção de Concreto Asfáltico (UCA) e dados relativos aos impactos negativos associados à unidade, visando identificar locais críticos, responsáveis pela origem dos impactos e a elaboração de mapa de riscos de acidentes ambientais graves.

\section{MATERIAL E MÉTODO}

\section{ÁREA DE ESTUDO}

A UCA operou no Município de Joinville/SC entre os anos de 1974 e 2002 (Figura 1), sendo que no ano de 2002, foram iniciados procedimentos de remediação e reabilitação da área, concluídos satisfatoriamente no ano de 2008.

Figura 1 - Croqui de localização da UCA (Coordenadas UTM 701.148,000E / 7.104.044,500S).

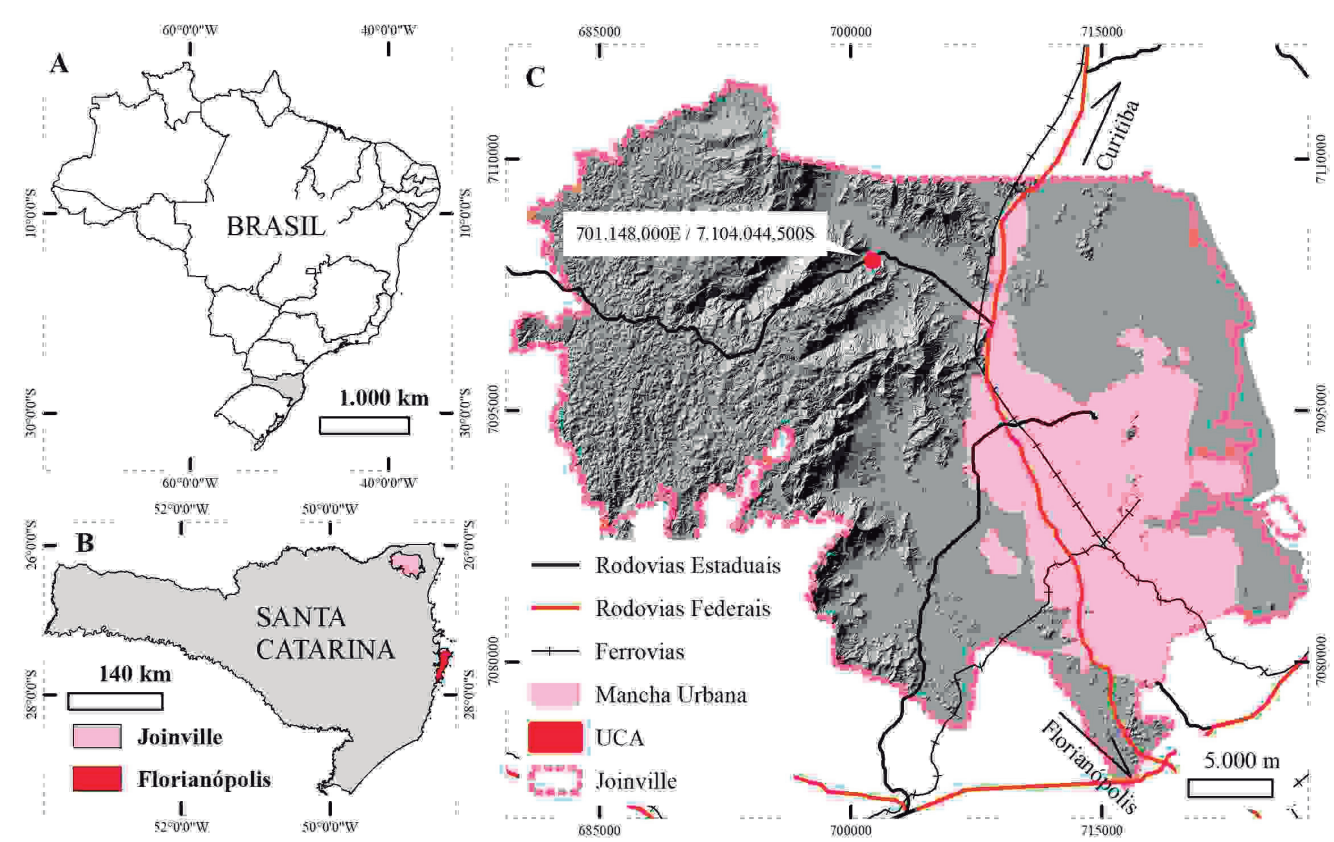

Bases de Dados: PMJ (2010), BRASIL (2019, 2020), SC (2020). 


\section{Características da unidade produtiva}

A UCA ocupava área de aproximadamente $22.000 \mathrm{~m}^{2}$ e correspondia a um complexo de beneficiamento, composto pelas subunidades e instalações constantes na Figura 2, no qual ocorria o processamento de cascalho polimítico de origem colúvio-aluvionar, retrabalhado e lavrado em ambiente fluvial ativo (Figura 3).

a) Subunidade de Cominuição, composta por Pátio de Estocagem e Alimentação de Cascalho Bruto (CB), Conjunto do Britador Primário de Mandíbulas (01), Grelha Vibratória (02), Pilha de Cascalho Britado (Cb), Pilha de Pedra Pulmão (PP), Túnel da Pilha de Pedra Pulmão (03), Conjunto do Britador Secundário de Mandíbulas (04), Conjunto do Britador Terciário Girosférico (05), Peneira Classificadora (06), Peneira Auxiliar (07), Subestação de Energia da Subunidade de Cominuição (08); Pilha de Pó de Brita (PO), Pilha de Brita 01 (B1), Pilha de Brita 02 (B2), Pilha de Brita 03 (B3);

b) Subunidade de Produção de Concreto Betuminoso Usinado a Quente (CBUQ) e de Produção Asfáltica Pré-misturada a Frio (PMF), composta por Tanque para Armazenamento de cerca de 5.0001 de Óleo Diesel (09), Conjunto de Tanques para Armazenamento de cerca de 50.0001 de Óleo de Baixo Ponto de Fluidez - BPF (10), Conjunto de Tanques para Armazenamento de cerca de $300 \mathrm{t}$ de Cimento Asfáltico de Petróleo - CAP (11 e 12), Conjunto da Caldeira a Lenha (13), Conjunto da Usina de CBUQ (14); Conjunto de Tanques para Armazenamento de cerca de 50.0001 de Emulsão Asfáltica (15), Conjunto da Usina de PMF (16), Barragem de Enrocamento e Lagoa para Armazenamento de cerca de 100.0001 de Rejeitos Asfálticos (BE), Lavador de Agregados (17), Conjunto do Tanque Duplo de Decantação do Lavador para Armazenagem de cerca de 300.0001 de Água com Sólidos em Suspensão (18), Subestação de Energia das Usinas e Áreas Administrativas (19), Pátio de Estocagem de Agregados Lavados e Alimentação das Usinas (EA);

c) Instalações Administrativas, com Conjunto da Balança (20), Conjunto do Escritório, Laboratório e Almoxarifado (21), Barragem de Terra do Reservatório de Represamento de Água Potável para cerca de 1.000.000 1(BR).

Figura 2 - Croqui das instalações da Unidade de Produção de Concreto Asfáltico (UCA).

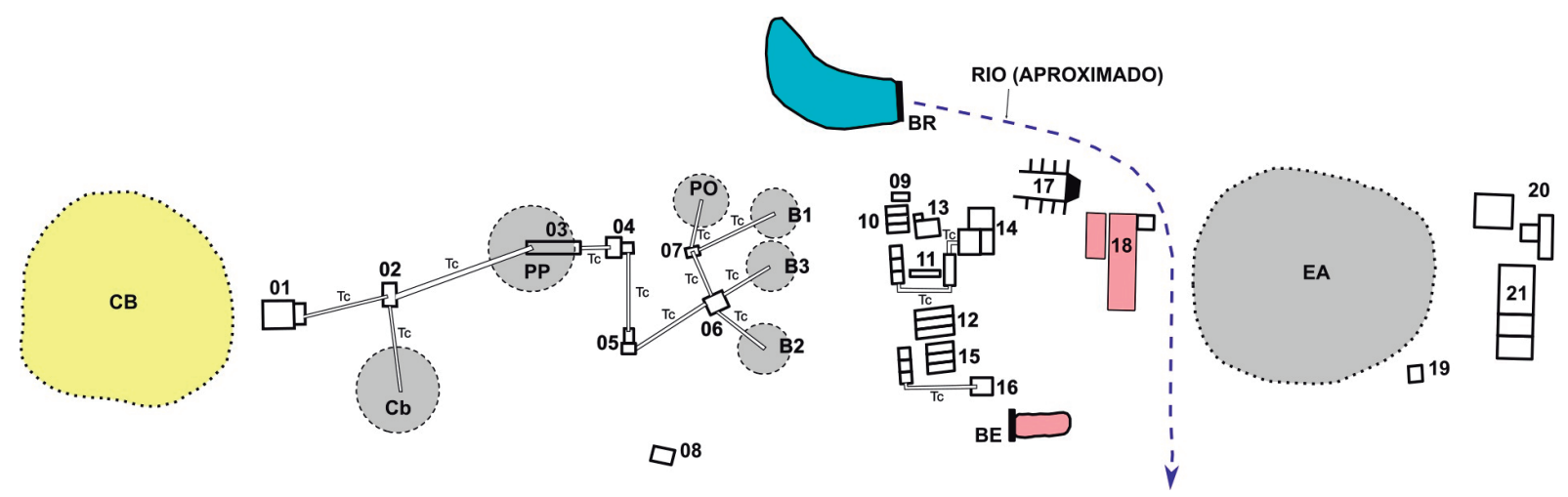

Tc: correias transportadoras. Sem escala. 
Figura 3 - Depósitos de cascalho polimítico, retrabalhados em ambiente fluvial e lavrados entre 1974 e 2002 para alimentação da UCA. Ponte Coberta sobre o Rio Cubatão, Joinville/SC. Fotografias capturadas no ano de 2014.
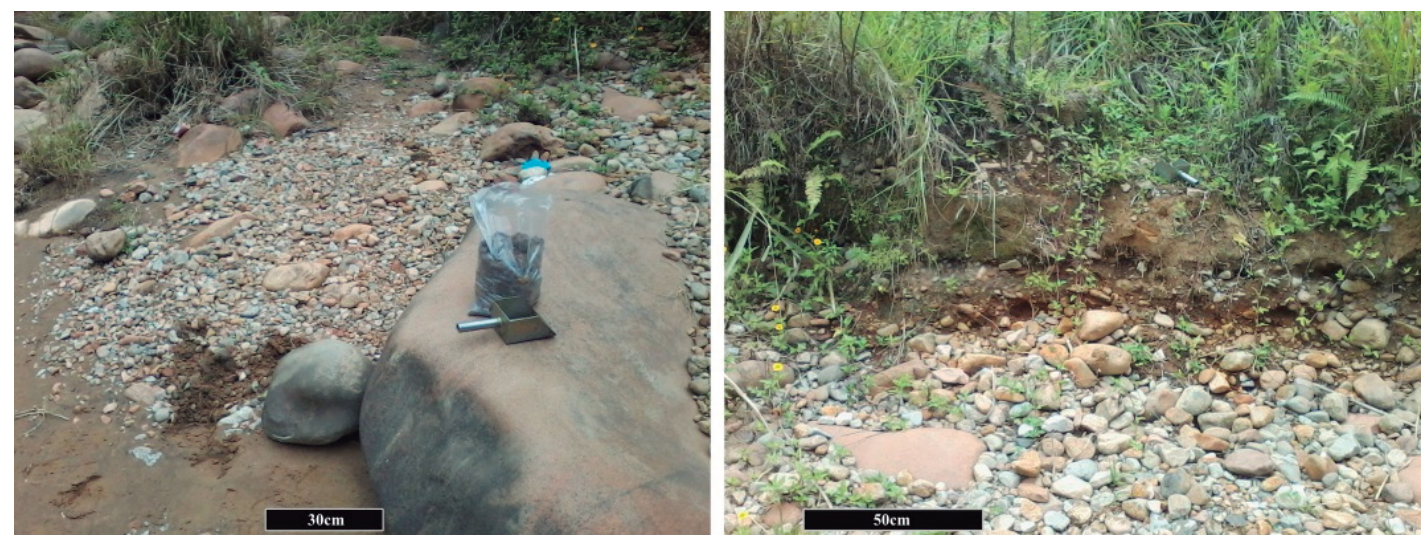

\section{Comprovação de degradação ambiental no horizonte histórico}

Após o encerramento das atividades operacionais, análises quantitativas de investigação ambiental que abrangeram a amostragem de solo em subsuperfície, água do aquífero livre, água de escoamento superficial e água oriunda de córrego que margeava o empreendimento, confirmaram a existência de área degradada associada à Área Diretamente Afetada (ADA) do empreendimento.

A degradação estava diretamente relacionada à Subunidade de Produção de Concreto Betuminoso Usinado a Quente (CBUQ) e de Produção Asfáltica Pré-misturada a Frio (PMF), e atingia cerca de $3.800 \mathrm{~m}^{2}$ da área total ou ADA da UCA. Nessa parcela, se originaram os impactos ambientais negativos ou contaminações analisadas neste trabalho, oriundas de sucessões de derramamentos de hidrocarbonetos ocorridos no horizonte histórico de operação do empreendimento.

Eventos de degradação, foram frequentes ao longo da vida útil da UCA (1974-2002), sendo relacionados a emissões irregulares de poeiras minerais e fuligens fugidias; poluição oriunda de descartes irregulares, vazamentos, derramamentos propositais e acidentais de hidrocarbonetos; extravasamentos dos tanques de decantação e da lagoa de rejeitos asfálticos; assoreamento e poluição de recursos hídricos superficiais; contaminação de vegetação ripária com hidrocarbonetos. Parte desses eventos, com recorrência em um mesmo ano, ocorreram em 1984, 1987, 1994, 1995 e 1996, abrangendo a poluição da circunvizinhança do empreendimento com poeiras minerais, a partir da subunidade de cominuição (Garcia \& Vieira, 1984; Borges, 1984; Fasanaro, 1984; Buschle, 1987; Jorgensen, 1987; Possamai, 1994; Buschle, 1994, 1995; Klug, 1996). Quanto aos eventos gerados na Subunidade de CBUQ-PMF, naqueles anos, podemos citar a poluição da circunvizinhança com fuligens de queima de óleo BPF, armazenamento proposital de resíduos de hidrocarbonetos em solo desprotegido, vazamentos acidentais de hidrocarbonetos dos tanques de armazenamento e lagoa de rejeitos asfálticos, lançamento proposital de hidrocarbonetos e vazamento de água de alta turbidez do tanque de decantação, afetando o rio próximo e a vegetação ripária (Garcia \& Vieira, 1984; Borges, 1984; Fasanaro, 1984; Buschle, 1987; Jorgensen, 1987; Possamai, 1994; Buschle, 1994, 1995; Klug, 1996). 
Entretanto e apesar de registrados, em geral esses eventos não foram devidamente qualificados quando da constatação das ocorrências. Em sua maioria, não foram realizadas rotinas de análises qualitativas e quantitativas para caracterização das consequências negativas no meio socioambiental e da magnitude dos impactos ocasionados. Denota-se que dentre os eventos de impactos negativos, apenas os relacionados à degradação por derramamento de hidrocarbonetos foram qualificados. Essa qualificação ocorreu à época do encerramento definitivo das atividades do empreendimento. Na ocasião, não foi possível individualizar todos os eventos de derramamento de hidrocarbonetos ao longo do horizonte histórico de operação do empreendimento. Entretanto, foi possível constatar que os efeitos negativos desses eventos de degradação, se acumularam e persistiram no meio ambiente por anos. Desse modo, os eventos foram analisados como um conjunto de situações periculosas, ocorridas nos anos de operação.

Eventos não associados aos hidrocarbonetos, não perduraram após o encerramento das atividades, ou seja, não deixaram traços identificáveis. Desse modo, os efeitos adversos desapareceram concomitantemente com a total desativação das operações, permitindo que o meio ambiente, naturalmente, retornasse aos parâmetros anteriores ao advento do empreendimento poluidor. Inclusive, possíveis efeitos negativos sobre o meio social, se existentes à época dos impactos, igualmente desapareceram com o encerramento operacional.

A comprovação de existência e qualificação dos impactos negativos, decorrentes de eventos de degradação pretéritos no horizonte histórico, ocorreu através de investigação de solos e recursos hídricos. Basicamente, a subsistência pós-empreendimento dos impactos ocasionados por derramamentos de hidrocarbonetos, ocorreu nesses meios.

A contaminação foi detectada através de identificação visual de exsudações de hidrocarbonetos no solo da Subunidade de CBUQ-PMF, de iridescência nas águas do rio afetado pela unidade e nas águas oriundas de chuvas, escoadas e acumuladas nas proximidades da citada subunidade (água de runoff). A detecção visual justificou as análises constantes na Tabela 1, realizadas após a desativação do empreendimento. A tabela apresenta resultados de amostras testadas para os parâmetros óleos e graxas minerais (OGM) e fenóis. As localizações dos pontos de coleta, constam na Figura 5.

Inicialmente, procedeu-se com a coleta da amostra 060/02, correspondente a água corrente da calha ativa de rio afetado pela UCA. Com a confirmação de presença de OGM e fenóis na amostra, a investigação prosseguiu com a amostragem de águas provenientes de chuvas recentes, escoadas no solo da Subunidade de CBUQ-PMF e acumuladas em valas de drenagem assoreadas (AA1, AA2 e AA4). Uma amostra denominada AA3 foi extraviada e seus resultados não foram avaliados. Essas amostras objetivaram determinar se o possível sítio contaminado, poderia ser lixiviado pela água de runoff após períodos chuvosos, com consequente ampliação da área degradada. As amostras apresentaram fenóis, indicados como associados às exsudações de hidrocarbonetos, pois considerou-se que o runoff, ao escoar no sítio contaminado durante períodos chuvosos, apresentava capacidade de rapidamente lixiviar fenóis para jusante, mas não tinha capacidade para o carreamento de OGM. 
Além disso, houve sondagem a trado, relacionada às amostras PA1 e PA2. A amostragem objetivou indicar se a contaminação estendia-se para as águas de subsuperfície do aquífero livre ou "lençol freático"; identificar visualmente se ocorriam contaminantes no solo sondado; e indicar se a contaminação com hidrocarbonetos estendia-se à subunidade de cominuição, situada na montante. A sondagem referente à amostra PA1 foi locada na subunidade de cominuição e atingiu cerca de $4 \mathrm{~m}$ de profundidade, sem a presença de água. Visualmente, os solos sondados não apresentaram resíduos de hidrocarbonetos.

A sondagem referente à amostra PA2 foi locada na subunidade de CBUQ-PMF e atingiu cerca de $2 \mathrm{~m}$ de profundidade, apresentando água contaminada com OGM e fenóis, além de solos com iridescência, considerada indício de contaminação, situação que justificou o prosseguimento das perfurações, objetivando a coleta de amostras de solos.

Duas perfurações foram executadas na Subunidade de CBUQ-PMF, denominadas PS1 e PS2. Estas, originaram as amostras PS1a e PS2a, correspondentes a solos coletados à profundidade de cerca de $1 \mathrm{~m}$. Adicionalmente, originaram as amostras PS1b e PS2b, coletadas nos mesmos furos, mas na profundidade de $2 \mathrm{~m}$. As amostras apresentaram indícios de contaminação. Entretanto, a perfuração PS2 indicou a presença de um aterro, executado sobre material contaminado com hidrocarbonetos. Desse modo, a amostra PS2a, foi coletada no trecho afetado por esse aterro, não apresentando OGM. Justificou-se a contaminação por fenóis dessa amostra, como decorrente de contaminação secundária através da percolação de água de escoamento superficial contaminada. Por outro lado, a amostra PS2b foi coletada na camada primariamente contaminada, apresentando OGM e fenóis.

Comprovada a existência da contaminação, prosseguiu-se com análises de monitoramento e acompanhamento dos parâmetros OGM e fenóis, até o início efetivo das medidas para total remoção das camadas de solo contaminadas com hidrocarbonetos. Simultaneamente, prosseguiu-se com sondagens para melhor delimitação da área degradada e indicação das porções do terreno em que seria necessária a remoção de camadas contaminadas de solo.

$\mathrm{Na}$ Tabela 2, constam as análises realizadas durante o detalhamento da investigação. As localizações dos pontos de coleta, constam na Figura 5. Essas análises focaram nas águas do aquífero livre nos pontos PMA e PMB, correspondentes a poços de monitoramento revestidos com, respectivamente, com 4 e 3,5m de profundidade. Os poços eram dotados de revestimento interno, filtro, pré-filtro, proteção sanitária, tampão e selo, sendo ideais para investigações e monitoramento por longo período de tempo. Ademais, focou-se no monitoramento das águas do rio afetado pela UCA, nos pontos PMM e PMJ. Os pontos, tanto de água subterrânea, como de água superficial, foram alocados na Subunidade de CBUQ-PMF, pois vislumbrava-se que a área degradada correspondia, aproximadamente, a essa subunidade. As análises denotaram uma variação nos parâmetros OGM e fenóis. Entretanto, corroboram a persistência da contaminação ao longo do tempo. 
Tabela 1 - Análises de investigação realizadas em 2002 e 2004.

\begin{tabular}{|c|c|c|c|c|c|}
\hline \multicolumn{3}{|c|}{ Amostra } & \multirow{2}{*}{ Parâmetro } & \multirow{2}{*}{ Unidade de Referência } & \multirow{2}{*}{ Resultado } \\
\hline Meio Amostral & Coleta & Nome & & & \\
\hline \multirow{2}{*}{ Água. Calha ativa de Rio } & \multirow{2}{*}{$01 / 04 / 02$} & \multirow{2}{*}{$060 / 02$} & Fenóis & $\mathrm{mg} / \mathrm{l} \mathrm{C6H5OH}$ & 0,15 \\
\hline & & & OGM & $\mathrm{mg} / \mathrm{l}$ & 5,1 \\
\hline \multirow{6}{*}{$\begin{array}{c}\text { Água de Escoamento } \\
\text { Superficial }\end{array}$} & \multirow{18}{*}{$16 / 12 / 04$} & \multirow{2}{*}{ AA1 } & Fenóis & $\mathrm{mg} / \mathrm{l} \mathrm{C6H5OH}$ & 0,008 \\
\hline & & & OGM & $\mathrm{mg} / \mathrm{l}$ & Ausentes \\
\hline & & \multirow{2}{*}{ AA2 } & Fenóis & $\mathrm{mg} / \mathrm{l} \mathrm{C6H5OH}$ & 0,005 \\
\hline & & & OGM & $\mathrm{mg} / \mathrm{l}$ & Ausentes \\
\hline & & \multirow{2}{*}{ AA4 } & Fenóis & $\mathrm{mg} / \mathrm{l} \mathrm{C6H5OH}$ & 0,16 \\
\hline & & & OGM & $\mathrm{mg} / 1$ & Ausentes \\
\hline \multirow{4}{*}{ Aquífero Livre } & & PA1 & Fenóis & $\mathrm{mg} / \mathrm{l} \mathrm{C6H5OH}$ & Seco \\
\hline & & IA1 & OGM & $\mathrm{mg} / \mathrm{l}$ & Seco \\
\hline & & DA? & Fenóis & $\mathrm{mg} / \mathrm{l} \mathrm{C6H5OH}$ & 0,025 \\
\hline & & FA2 & OGM & $\mathrm{mg} / \mathrm{l}$ & 12,19 \\
\hline \multirow{8}{*}{ Solo em Subsuperfície } & & \multirow{2}{*}{ PS1a } & Fenóis & $\mathrm{mg} / \mathrm{kg}$ & 1,16 \\
\hline & & & OGM & $\mathrm{mg} / \mathrm{kg}$ & 62,43 \\
\hline & & \multirow{2}{*}{ PS1b } & Fenóis & $\mathrm{mg} / \mathrm{kg}$ & 0,47 \\
\hline & & & OGM & $\mathrm{mg} / \mathrm{kg}$ & 320,65 \\
\hline & & \multirow{2}{*}{ PS2a } & Fenóis & $\mathrm{mg} / \mathrm{kg}$ & 0,69 \\
\hline & & & OGM & $\mathrm{mg} / \mathrm{kg}$ & Ausentes \\
\hline & & \multirow{2}{*}{$\mathrm{PS} 2 \mathrm{~b}$} & Fenóis & $\mathrm{mg} / \mathrm{kg}$ & 0,23 \\
\hline & & & OGM & $\mathrm{mg} / \mathrm{kg}$ & 102,64 \\
\hline
\end{tabular}

A amostra PA1 não foi coletada por ausência de água no fundo do furo. A sondagem atingiu cerca de $4 \mathrm{~m}$ de profundidade. A amostra PA2 foi coletada a $2 \mathrm{~m}$ de profundidade. As amostras PS1a e PS2a, correspondem a amostras de solos coletadas a $1 \mathrm{~m}$ de profundidade, enquanto as amostras PS1b e PS2b, foram coletadas a 2m de profundidade. OGM: óleos e graxas minerais.

Tabela 2 - Análises de investigação e monitoramento realizadas entre 2006 e 2008.

\begin{tabular}{|c|c|c|c|c|c|}
\hline \multicolumn{3}{|c|}{ Amostra } & \multirow{2}{*}{ Parâmetro } & \multirow{2}{*}{ Unidade de Referência } & \multirow{2}{*}{ Resultado } \\
\hline Meio Amostral & Coleta & Ponto Amostral & & & \\
\hline \multirow{4}{*}{ Aquífero Livre } & \multirow{8}{*}{$31 / 01 / 06$} & & Fenóis & $\mathrm{mg} / \mathrm{l} \mathrm{C6H5OH}$ & 0,042 \\
\hline & & PMA & OGM & $\mathrm{mg} / \mathrm{l}$ & Ausentes \\
\hline & & & Fenóis & $\mathrm{mg} / \mathrm{l} \mathrm{C6H5OH}$ & 0,017 \\
\hline & & PMB & OGM & $\mathrm{mg} / \mathrm{l}$ & Ausentes \\
\hline \multirow{4}{*}{ Água. Calha ativa de Rio. } & & \multirow{2}{*}{ PMM } & Fenóis & $\mathrm{mg} / \mathrm{l} \mathrm{C6H} 5 \mathrm{OH}$ & Ausentes \\
\hline & & & OGM & $\mathrm{mg} / 1$ & Ausentes \\
\hline & & \multirow{2}{*}{ PMJ } & Fenóis & $\mathrm{mg} / \mathrm{l} \mathrm{C6H5OH}$ & Ausentes \\
\hline & & & OGM & $\mathrm{mg} / \mathrm{l}$ & Ausentes \\
\hline \multirow{4}{*}{ Aquífero Livre } & \multirow{8}{*}{$28 / 07 / 06$} & \multirow{2}{*}{ PMA } & Fenóis & $\mathrm{mg} / 1 \mathrm{C} 6 \mathrm{H} 5 \mathrm{OH}$ & 0,004 \\
\hline & & & OGM & $\mathrm{mg} / \mathrm{l}$ & 6,0 \\
\hline & & \multirow{2}{*}{ PMB } & Fenóis & $\mathrm{mg} / \mathrm{l} \mathrm{C6H5OH}$ & 0,003 \\
\hline & & & OGM & $\mathrm{mg} / \mathrm{l}$ & 5,1 \\
\hline \multirow{4}{*}{ Água. Calha ativa de Rio. } & & \multirow{2}{*}{ PMM } & Fenóis & $\mathrm{mg} / \mathrm{l} \mathrm{C6H5OH}$ & 0,001 \\
\hline & & & OGM & $\mathrm{mg} / \mathrm{l}$ & Ausentes \\
\hline & & \multirow{2}{*}{ PMJ } & Fenóis & $\mathrm{mg} / \mathrm{l} \mathrm{C6H5OH}$ & 0,004 \\
\hline & & & OGM & $\mathrm{mg} / \mathrm{l}$ & Ausentes \\
\hline
\end{tabular}




\begin{tabular}{|c|c|c|c|c|c|}
\hline \multirow{4}{*}{ Aquífero Livre } & \multirow{8}{*}{$23 / 01 / 07$} & \multirow{2}{*}{ PMA } & Fenóis & $\mathrm{mg} / \mathrm{l} \mathrm{C6H5OH}$ & 0,005 \\
\hline & & & OGM & $\mathrm{mg} / \mathrm{l}$ & Ausentes \\
\hline & & \multirow{2}{*}{ PMB } & Fenóis & $\mathrm{mg} / \mathrm{l} \mathrm{C6H5OH}$ & 0,002 \\
\hline & & & OGM & $\mathrm{mg} / \mathrm{l}$ & Ausentes \\
\hline \multirow{4}{*}{ Água. Calha ativa de Rio. } & & \multirow{2}{*}{ PMM } & Fenóis & $\mathrm{mg} / \mathrm{l} \mathrm{C6H5OH}$ & 0,001 \\
\hline & & & OGM & $\mathrm{mg} / 1$ & Ausentes \\
\hline & & \multirow{2}{*}{ PMJ } & Fenóis & $\mathrm{mg} / \mathrm{l} \mathrm{C6H5OH}$ & 0,002 \\
\hline & & & OGM & $\mathrm{mg} / \mathrm{l}$ & Ausentes \\
\hline \multirow{4}{*}{ Aquífero Livre } & \multirow{8}{*}{$19 / 07 / 07$} & PMA & Fenóis & $\mathrm{mg} / \mathrm{l} \mathrm{C6H5OH}$ & 0,005 \\
\hline & & $1 \mathrm{NHA}$ & OGM & $\mathrm{mg} / \mathrm{l}$ & Ausentes \\
\hline & & PMB & Fenóis & $\mathrm{mg} / \mathrm{l} \mathrm{C6H} 5 \mathrm{OH}$ & 0,002 \\
\hline & & IVID & OGM & $\mathrm{mg} / \mathrm{l}$ & Ausentes \\
\hline \multirow{4}{*}{ Água. Calha ativa de Rio } & & \multirow{2}{*}{ PMM } & Fenóis & $\mathrm{mg} / \mathrm{l} \mathrm{C6H5OH}$ & 0,001 \\
\hline & & & OGM & $\mathrm{mg} / \mathrm{l}$ & Ausentes \\
\hline & & \multirow{2}{*}{ PMJ } & Fenóis & $\mathrm{mg} / \mathrm{l} \mathrm{C6H5OH}$ & 0,002 \\
\hline & & & OGM & $\mathrm{mg} / \mathrm{l}$ & Ausentes \\
\hline \multirow{4}{*}{ Aquífero Livre } & \multirow{8}{*}{$06 / 02 / 08$} & \multirow{2}{*}{ PMA } & Fenóis & $\mathrm{mg} / \mathrm{l} \mathrm{C} 6 \mathrm{H} 5 \mathrm{OH}$ & 0,017 \\
\hline & & & OGM & $\mathrm{mg} / \mathrm{l}$ & 19,4 \\
\hline & & \multirow{2}{*}{ PMB } & Fenóis & $\mathrm{mg} / \mathrm{l} \mathrm{C6H5OH}$ & 0,003 \\
\hline & & & OGM & $\mathrm{mg} / 1$ & 4,6 \\
\hline \multirow{4}{*}{ Água. Calha ativa de Rio. } & & \multirow{2}{*}{ PMM } & Fenóis & $\mathrm{mg} / \mathrm{l} \mathrm{C6H5OH}$ & Ausentes \\
\hline & & & OGM & $\mathrm{mg} / \mathrm{l}$ & 3,0 \\
\hline & & \multirow{2}{*}{ PMJ } & Fenóis & $\mathrm{mg} / \mathrm{l} \mathrm{C6H} 5 \mathrm{OH}$ & 0,002 \\
\hline & & & OGM & $\mathrm{mg} / 1$ & 0,2 \\
\hline
\end{tabular}

Os pontos PMA e PMB, correspondem a pontos de amostragem em poços de monitoramento, respectivamente com 4 e 3,5m de profundidade. OGM: óleos e graxas minerais.

Visando o detalhamento das informações oriundas dos furos para coleta de água do aquífero livre PA1 e PA2, a investigação avançou com etapa de sondagens exploratórias para interceptação de camadas contaminadas de solos e sedimentos, com delimitação da área degradada (Figura 5). A investigação indicou que o substrato original ou natural do terreno é basicamente constituído por camada métrica de argila marrom a cinza, raramente com resquícios de matéria orgânica e de rocha decomposta, sobreposta a cascalho polimítico.

O substrato geneticamente corresponde a depósitos colúvio-aluvionares continentais, formados sob condições semiáridas, e a aluviões atuais, acumulados em planícies de inundação, terraços, calhas da rede fluvial e resultantes do retrabalho dos depósitos mais antigos. A composição em óxidos desses depósitos, obtida através de fluorescência de raios x (FRX), indica que o substrato é, principalmente, constituído por $\mathrm{SiO}_{2}$ (74,48 a 78,72\%) (Maciel-Pinto, 2014a, 2014b, 2020b). Secundariamente, com $\mathrm{Al}_{2} \mathrm{O}_{3}\left(9,41\right.$ a 13,19\%), $\mathrm{Fe}_{2} \mathrm{O}_{3}\left(2,47\right.$ a 3,23\%), $\mathrm{K}_{2} \mathrm{O}\left(2,38\right.$ a 2,78\%), $\mathrm{Na}_{2} \mathrm{O}(2,11$ a 2,32\%), $\mathrm{CaO}(1,42$ a $1,79 \%)$ e menores quantidades de $\mathrm{MgO}(0,60$ a $0,87 \%), \mathrm{TiO}_{2}(0,37$ a $0,55 \%), \mathrm{P}_{2} \mathrm{O}_{5}(0,05$ a $0,12 \%)$ e $\mathrm{MnO}(0,05$ a 0,07\%) (Maciel-Pinto, 2014a, 2014b, 2020b).

As sondagens exploratórias corroboraram que na ADA, sobre esse substrato original, executou-se aterramento. O aterro correspondia a camadas decimétricas de saibro e cascalho compactadas, 
executadas sobre as porções de terreno argiloso, para reforço do substrato e, por vezes, para cobrimento das porções contaminadas com hidrocarbonetos. As sondagens também indicaram que a contaminação por hidrocarbonetos, frequentemente em estado viscoso ou "não curado", centrava-se na Subunidade de CBUQ-PMF, constituindo a área degradada, fonte de contaminação de águas e solos (furos F05, F06, F07). Os demais furos (F01, F02, F03, F04, F08, F09, F10), denotaram que a contaminação não se estendia para a Subunidade de Cominuição, Pátio de Estocagem de Agregados e Instalações Administrativas.

Infere-se que a expansão da contaminação ocorria através do escoamento superficial e da percolação das águas das chuvas nas camadas dos aterros contaminados. As águas propiciariam a progressiva lixiviação dos contaminantes não curados dos aterros e o transporte para camadas sotopostas, não contaminadas. Além disso, a água propiciaria o escoamento de contaminantes da área degradada para locais próximos e não contaminados na jusante, como no rio situado na ADA, obedecendo ao padrão de escoamento superficial do terreno.

A remediação da área degradada, conduziu à remoção de cerca de $3.200 \mathrm{~m}^{3}$ de solos, sedimentos e aterros contaminados com hidrocarbonetos, atingindo profundidade de até $2,30 \mathrm{~m}$, sendo que cerca de $1.200 \mathrm{~m}^{3}$, correspondiam a material contaminado com resíduos asfálticos "não curados" ou em estado de líquido com alta viscosidade (Trojan, 2005) (Figura 4, Tabela 2).

Figura 4 - Exemplo de solos contaminados com resíduos asfálticos “não curados” removidos da UCA.
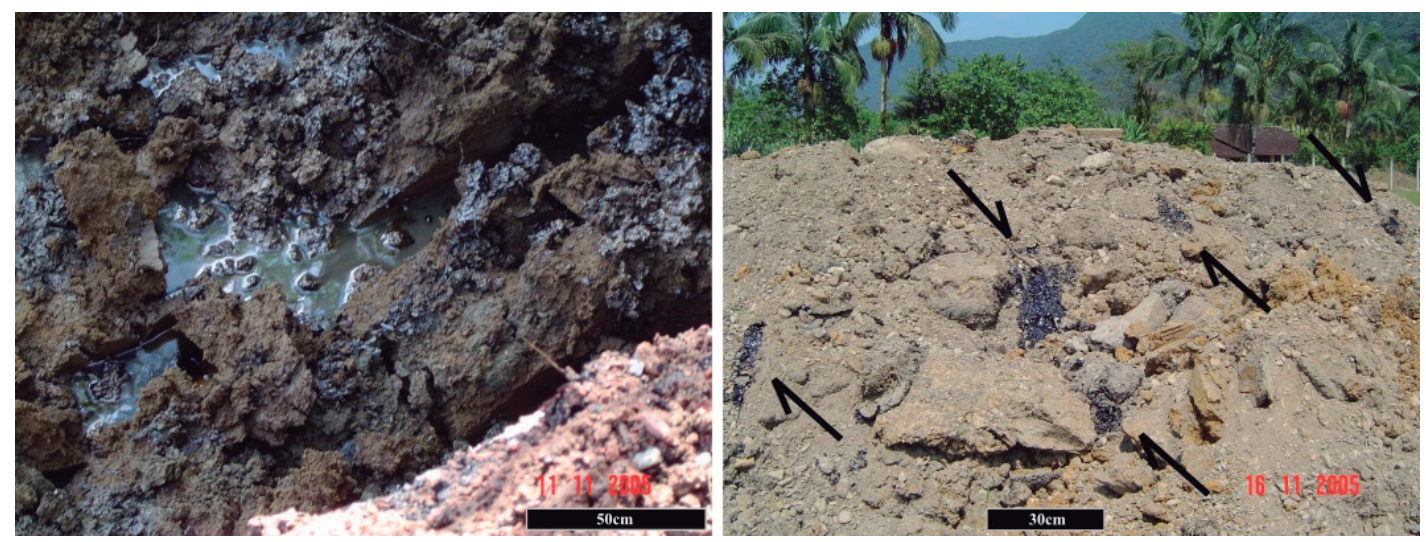

Modificado de: Trojan (2005).

\section{DISCUSSÃO}

A constatação da existência de conjunto de eventos não individualizáveis e pretéritos, se tornou possível, pois os eventos danosos ocorridos ao longo do horizonte, geraram uma área degradada persistente e impactos ambientais relevantes, de longa duração, os suplantaram a 
vida útil do empreendimento. Essa área degradada apresentava contaminação por óleos e graxas minerais, além de fenóis. Desse modo, pode-se indicar quais foram as instalações de origem das contaminações, além de indicar quais as instalações com maior probabilidade de ocorrência de impactos relevantes, de longa duração e de maior gravidade em empreendimentos semelhantes ou correlacionáveis.

Após a desmobilização da UCA, amostras coletadas nos pontos 060/02, PMM e PMJ, denotaram a presença de hidrocarbonetos (óleos e graxas minerais e fenóis) nas águas fluviais de rio afetado pela unidade. A contaminação estendia-se aos solos e águas subterrâneas, conforme amostras coletadas nos pontos PS1a, PS1b, PS2a, PS2b, PA2, PMA e PMB. Já amostras coletadas nos pontos AA1, AA2 e AA4, correspondentes a águas das chuvas, escoadas sobre o solo em antigas valas de escoamento superficial da UCA, indicaram o arraste superficial de fenóis em períodos de precipitação pluviométrica (Tabelas 1 e 2, Figura 5).

Investigação de subsolo, através dos furos de sondagem F05, F06, F07 e dos furos de coleta de água subterrânea PA2, PMA e PMB, identificou o foco da contaminação, como associado aos aterros contaminados por rejeitos asfálticos e hidrocarbonetos em geral (Figura 5). Especificamente, a área degradada, origem das contaminações, correspondia ao local outrora ocupado pela Subunidade de CBUQ-PMF (Figuras 3 e 5).

Os aterros contaminados continham, principalmente, mistura de emulsão asfáltica, cimento asfáltico de petróleo (CAP) e concreto asfáltico, oriundos de despejos irregulares, além de diversos casos de vazamentos acidentais. Esses casos, inclusive abrangiam o extravasamento e vazamento de efluentes líquidos da lagoa de rejeitos, além do rompimento de tanques de armazenamento alocados na subunidade.

A partir desse sítio ou área original de degradação, foco de contaminação dos solos, houve a migração de hidrocarbonetos carreáveis pela água, genericamente óleos, graxas e fenóis, principalmente oriundos dos resíduos "não curados" nos aterros. A migração foi influenciada pelas águas pluviais que, ao percolarem nas camadas dos aterros contaminados, proporcionavam o transporte de OGM e fenóis para camadas, relativamente, mais profundas do horizonte de solos e sedimentos, inclusive atingindo o aquífero livre (lençol freático).

A água percolada, lixiviava os resíduos que contaminavam o sítio degradado e propiciava o transporte em subsuperfície de contaminantes, conduzindo à poluição de recursos hídricos superficiais e subterrâneos.

Inclusive, as amostragens realizadas nos pontos AA1, AA2 e AA4, demonstram que durante chuvas, após atingir as camadas superficiais dos aterros contaminados, a água de escoamento tinha sobremaneira, capacidade de rapidamente carrear fenóis e ampliar a área degradada. A extrema 
mobilidade dos fenóis em águas superficiais, também levando em conta os resultados dos pontos amostrais apresentados nas Tabelas 1 e 2, indica que estes podem ser amplamente utilizados como indicadores ou rastreadores de sítios contaminados com hidrocarbonetos. Sendo que, no caso de sítios contaminados identificados, a ausência de fenóis em águas superficiais por longo período, após a conclusão de procedimentos de remediação e reabilitação, podem indicar sucesso e efetiva cessação da contaminação.

\section{MAPEAMENTO DE RISCOS DE ACIDENTES AMBIENTAIS GRAVES}

Conhecendo as instalações de origem, a dinâmica e a abrangência da contaminação, foi possível elaborar mapa de riscos de acidentes ambientais graves, o qual pode ser reproduzido para empreendimentos semelhantes ou correlacionáveis.

Infere-se que nesses empreendimentos, os riscos associados aos impactos duradouros no tempo e no espaço, que não desaparecerão naturalmente com encerramento da atividade e que subsistirão alterando negativamente o meio ambiente, estão associados às instalações de armazenamento e beneficiamento de substâncias ou compostos químicos potencialmente poluidores. Estas, por sua vez essenciais no processo produtivo e armazenadas em volumes, ou tonelagens que viabilizam a subsistência dos impactos após o encerramento definitivo das operações.

No presente caso, os impactos ambientais efetivamente comprovados através de análises químicas e investigação de subsolo, estavam centrados e tiveram origem na Subunidade de CBUQ-PMF, gerando área degradada de cerca de $3.800 \mathrm{~m}^{2}$. Estes impactos perduraram após a desativação da UCA e se relacionavam com as seguintes instalações de apoio: Tanque para Armazenamento de Óleo Diesel (09), Conjunto de Tanques para Armazenamento de BPF (10), Conjunto de Tanques para Armazenamento CAP (11 e 12), Conjunto da Usina de CBUQ (14); Conjunto de Tanques para Armazenamento de Emulsão Asfáltica (15), Conjunto da Usina de PMF (16), Barragem de Enrocamento e Lagoa para Armazenamento de Rejeitos Asfálticos (BE) (Figuras 03 e 05).

A Figura 05A apresenta modelo de elevação que remete à configuração topográfica do local ocupado pela UCA durante a sua vida útil. Na figura, ocorre a individualização das instalações de apoio que originaram o conjunto de eventos de degradação e as contaminações verificadas entre os anos de 2002-2008, em relação a pontos de amostragem e investigação de subsolo. Denota-se a presença de um rio na Área Diretamente Afetada (ADA) pelo empreendimento, nas imediações das instalações que originaram o conjunto de eventos de degradação. O rio pertence à bacia do Rio Cubatão, sub-bacia do Rio Seco e apresenta pequeno porte $(<10 \mathrm{~m}$ de largura). 
Figura 05 - Mapeamento de riscos de acidentes ambientais graves e de instalações de apoio que originaram o conjunto de eventos de degradação ou de poluição.

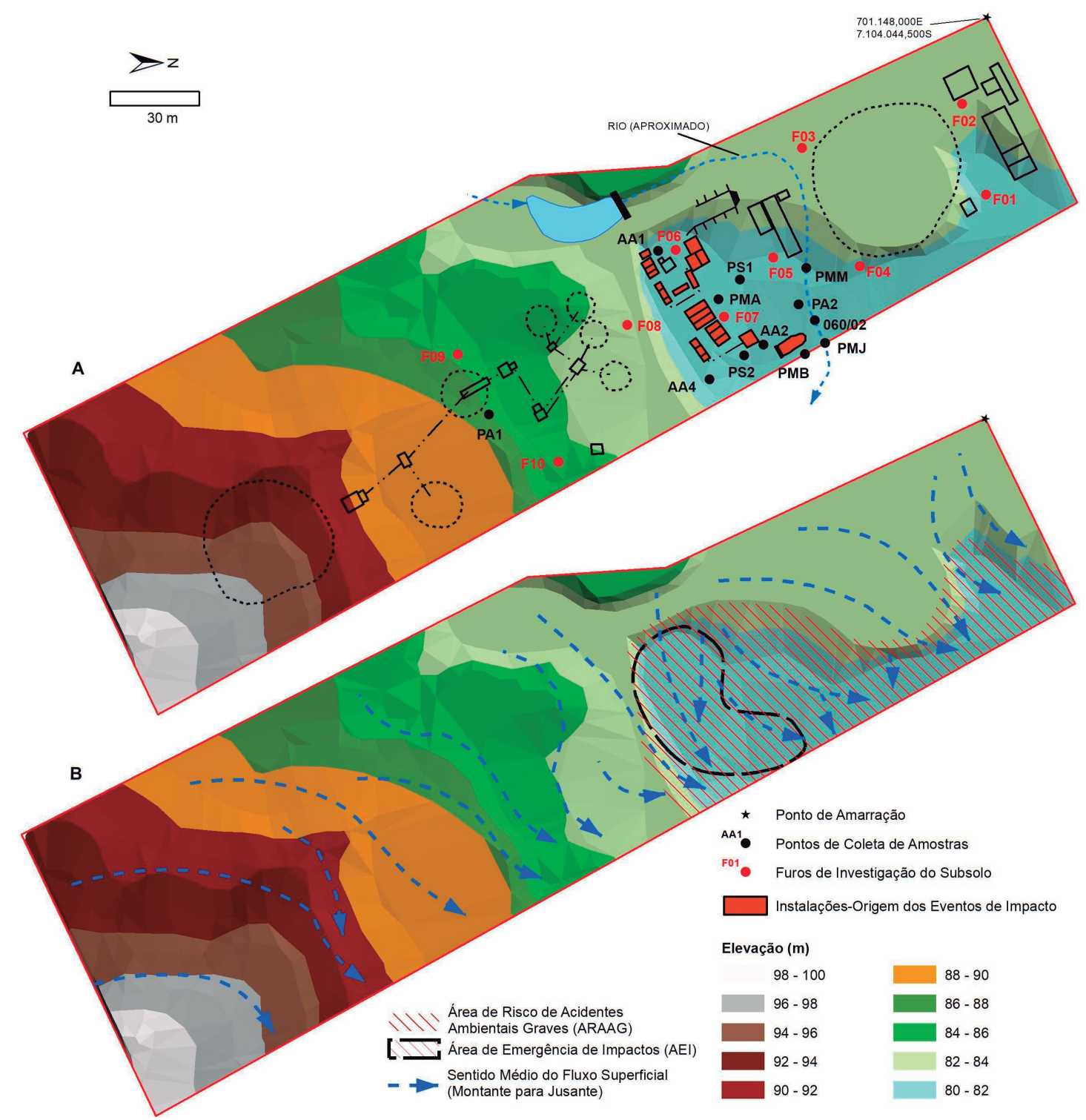

Na Figura 5B, há a indicação do sentido médio ou geral do fluxo da água de escoamento superficial, da montante do terreno para a jusante. Especificamente, em direção aos principais rios da sub-bacia e bacia hidrográfica, ou seja, os Rios Seco e Cubatão. A direção média foi obtida através da análise dos padrões topográficos de escoamento superficial apresentados pelo terreno. A figura indica, ainda, a Área de Emergência de Impactos (AEI), correspondente aproximadamente às instalações problemáticas, responsáveis pelo surgimento da área degradada e correspondente ao sítio original de degradação, fonte de contaminantes.

O fluxo superficial indica que há a tendência de que contaminantes carreáveis pelas águas de escoamento e percoladas, presentes na área degradada, sejam transportados para as cotas mais baixas do terreno, conforme observado durante as amostragens constantes nas Tabelas 1 e 2. No contexto 
exclusivo da Área Diretamente Afetada (ADA) pelo empreendimento, o posicionamento da Subunidade de CBUQ-PMF em local na jusante das demais instalações da UCA, em um baixio topográfico, permitiu que as contaminações ficassem centradas na própria subunidade, impedindo a expansão da contaminação. Desse modo, óleos, graxas e fenóis carreáveis pelas águas, não atingiram porções do empreendimento fora do baixio topográfico, concentrando-se em cerca de $3.800 \mathrm{~m}^{2}$ dos cerca de $22.000 \mathrm{~m}^{2}$.

Nesse caso, os resíduos não curados e viscosos, podem ser considerados como a principal fonte de óleos, graxas e fenóis constatados nos solos e nas águas em geral. Tal, tendo em vista que seus componentes são facilmente lixiviados quando percolados por água, possuindo capacidade de contaminar áreas contíguas ao sítio original de degradação. Inclusive, denota-se que a água configura meio preferencial de dispersão e ampliação da área degradada.

Considerando os padrões do fluxo superficial e os padrões topográficos, a Figura 5B demonstra a principal Área de Risco de Acidentes Ambientais Graves, ou a área preferencialmente contaminada no caso de ocorrência de evento de degradação na Área de Emergência de Impactos, ocupada pelas principais instalações potencialmente poluidoras, identificadas anteriormente.

Entretanto, ainda que a Figura 5B esteja centrada na ADA correspondente ao empreendimento, áreas contíguas, situadas em cotas iguais ou inferiores às da subunidade e topograficamente associadas, são preferencialmente atingidas no caso de eventos de degradação na AEI.

Inclusive, rios nas proximidades da AEI, conforme o situado na ADA do empreendimento, podem configurar como meio dispersante e preferencial de contaminantes no próprio empreendimento e para áreas contíguas.

Finalmente, tendo em conta os mapas constantes na Figura 5, as instalações beneficiadoras e armazenadoras de hidrocarbonetos, correspondem às áreas com iminência de geração de impactos negativos ou Áreas de Emergência de Impactos (AEI) das Unidades de Produção de Concreto Asfáltico (UCA), ou simplesmente usinas de asfalto. Tratam-se dos locais com maior risco de geração de impactos ambientais graves e de longa duração.

Em caso de eventos de degradação, a AEI será primeiramente afetada. Porém, a situação topográfica do terreno e do fluxo hídrico, será preponderante para a redistribuição de contaminantes. A existência de rios ou recursos semelhantes nas imediações da AEI, poderá configurar meio preferencial de redistribuição. Inclusive, drenagens de origem antrópica, como valas de escoamento, dentre outras, igualmente poderão figurar como meio preferencial de redistribuição de contaminantes para áreas em cotas, relativamente, mais baixas.

Desse modo, ao identificar a AEI, deve ser procedido com estudo visando analisar as condições de redistribuição de contaminantes, especialmente levando em conta o fluxo hídrico e a topografia do terreno. Através desse procedimento, será obtida a Área de Riscos de Acidentes Ambientais Graves (ARAAG). Esta, corresponde a área que será, preferencialmente, atingida por acidentes de cunho ambiental na AEI. 
Esse contexto indica que na ADA, a AEI e a ARAAG, em empreendimentos correlacionáveis, devem centrar os esforços de controle de impactos, como bacias e barragens de contenção, e de monitoramento de impactos ambientais negativos, como poços, sistemas de alerta e pontos amostrais de monitoramento periódico. Instalações existentes na AEI devem, igualmente, ser alvo preferencial de checagem e manutenção, em especial de tanques ou vasos de armazenamento de produtos potencialmente poluidores. Desse modo, será possível otimizar os investimentos em controle, monitoramento e manutenção, com vistas à redução dos riscos socioambientais, maximizando a capacidade de detecção de impactos ambientais graves, duradouros no tempo e no espaço, antes do agravamento e da expansão dos eventos de degradação. Assim, a AEI e a ARAAG devem receber os maiores esforços de para a contenção de possíveis eventos de degradação ambiental que venham a perdurar no tempo e progressivamente a se expandir no espaço.

\section{CONSIDERAÇÕES FINAIS}

A Resolução CONAMA 001/1986 define impacto ambiental como qualquer alteração das propriedades físicas, químicas e biológicas do meio ambiente, resultante de atividades antrópicas e que afetam a saúde, a segurança e o bem-estar da população, as atividades sociais e econômicas, a biota, as condições estéticas e sanitárias do meio ambiente, ou qualidade dos recursos ambientais.

O impacto decorre de intervenção humana que ocasiona alterações positivas ou negativas, tanto no meio ambiente, como no social. Se inexiste influência direta, ou indireta da ação antrópica sobre o meio, então inexiste impacto (Maciel-Pinto, 2020a). Depreende-se que, em maior ou menor grau, direta ou indiretamente, as intervenções impostas ao meio ambiente, ocasionarão alterações no próprio meio social, positivas ou negativas, tendo em vista que este é dependente daquele. Por outro lado, a origem do impacto no meio ambiente, estará sempre atrelada às pressões sociais.

Como o senso técnico comum indica, os impactos ambientais decorrentes das atividades humanas são compreensíveis, porém, não são aceitáveis. Assim, torna-se necessária a constante revisão e melhora dos métodos de Avaliação de Impactos Ambientais (AID).

No caso das Unidades de Produção de Concreto Asfáltico (UCA), ou simplesmente Usinas de Asfalto, ferramentas como o mapeamento de processos, a análise do histórico de eventos poluidores em empreendimentos correlacionáveis e o mapeamento de riscos de acidentes ambientais, são promissores. Neste trabalho, demonstrou-se que através de uma breve rotina de mapeamento de processos, executada através da análise de um croqui básico de instalações, e a recuperação de dados históricos que remete a conjunto de eventos pretéritos de degradação, foi possível elaborar um mapa de riscos que indicou a área preferencial de geração de impactos em uma usina de asfaltos. Desse modo, conclui-se que:

- É preponderante que o responsável pela AIA, tome conhecimento do histórico de impactos socioambientais de empreendimentos correlacionáveis; 
- A AIA de um empreendimento potencialmente poluidor, pode ser substancialmente enriquecida através da análise de informações compiladas de fontes históricas, recuperáveis através de pesquisa bibliográfica;

- Informações históricas sobre impactos socioambientais, medidas de controle, monitoramento e mitigação outrora aplicadas em empreendimentos que foram foco de eventos graves de degradação ambiental, podem auxiliar no refinamento da AIA, na identificação de situações e instalações de risco em empreendimentos correlacionáveis em fase de projeto;

- O refinamento da AIA e a identificação de situações de risco de acidentes ambientais, podem auxiliar na minimização de deficiências na identificação e na classificação dos impactos ambientais prováveis, atividades estas, por vezes, permeadas de subjetividade, percepções individuais e julgamentos de valor;

- Através da compilação de dados de fontes históricas e da identificação de situações e instalações de risco, com sobreposição de dados sobre o ambiente físico, como aqueles relativos à topografia e ao direcionamento do fluxo hídrico, é possível mapear as áreas de risco, preponderantes para a origem de impactos ou de origem de degradação e preponderantes para a redistribuição de contaminantes a partir desse sítio;

- O mapeamento de riscos, ao identificar os sítios preponderantes para a origem de impactos graves e os sítios em que ocorrerá a redistribuição de contaminantes, pode auxiliar na maximização do esforço e dos recursos de monitoramento, controle e mitigação de impactos socioambientais, proporcionando melhor alocação desses esforços e recursos.

Finalmente, para a recuperação fidedigna de informações históricas sobre impactos socioambientais, considera-se importante a divulgação, compilação e análise de eventos de impactos comprovados, no meio científico especializado, através de notas ou notícias, artigos, revisões bibliográficas, resumos, dissertações, teses, etc. Desse modo, a coletânea de situações de vulnerabilidade de empreendimentos potencialmente poluidores, revisada por pares, formará o escopo da análise do histórico de impactos dos empreendimentos correlacionáveis, com alto grau de confiança técnica e científica.

\section{REFERÊNCIAS}

BORGES, C. L. S. B. Resposta à Notificação de 27 de março de 1984 e Memorial Descritivo do Empreendimento. 21p. 1984.

BUSCHLE, N. G. Laudo Técnico de Vistoria. 2p. 1987.

BUSCHLE, N. G. Auto de Infração Ambiental N.04519. 2p. 1994. 
BUSCHLE, N. G. Relatório Técnico de Viagem e Auto de Infração N. 05268. 5p. 1995.

BRASIL. Instituto Brasileiro de Geografia e Estatística. Malha Municipal e Estadual Digital da Divisão Político-Administrativa Brasileira. Arquivos shapefile. Sem escala. 2019.

BRASIL. Ministério da Infraestrutura. Mapas e Bases dos Modos de Transporte. Arquivos shapefile. Sem escala. 2020.

FASANARO, R. Parecer Interno e Relatório Técnico de Vistoria de 11 de julho de 1984. 2p. 1984.

GARCIA, M. C. S. \& VIEIRA, J. M. M. Ofício AR 0613 de 27 de março de 1984: Notificação para Adequação do Empreendimento e Relatório/Parecer Técnico de Vistoria. 4p. 1984.

JORGENSEN, A. Ofício GRN 00415. 2p. 1987.

KLUG, J. F. Auto de Infração N.08950. 7p. 1996.

MACIEL-PINTO, F. Relatório Final de Pesquisa Mineral - Área Três Rios do Norte, Jaraguá do Sul/SC. 162p. 2014a.

MACIEL-PINTO, F. Relatório Final de Pesquisa Mineral - Área Rio da Prata-Cubatão, Joinville/ SC. 162p. 2014b.

MACIEL-PINTO, F. Depósitos minerais e previsão de Impactos Ambientais: Os modelos genéticos Perau e Panelas no estado do Paraná (Brasil). Revista Brasileira de Meio Ambiente, 8(1):70-86. 2020a.

MACIEL-PINTO, F. Relatório Final de Pesquisa Mineral - Área Vila Lalau, Jaraguá do Sul/SC. 162p. 2020 b.

MELLO, L. A. Auto de Infração Ambiental N.04517. 1p. 1994.

PMJ - Prefeitura Municipal de Joinville. Modelo de Sombreamento do Município de Joinville. Arquivos shapefile. Sem escala. 2010.

SANDOVAL, M.D.S. \& Cerri, L.E.D.S. Proposta de padronização em avaliação de impactos ambientais. Revista Engenharia Ambiental, 6 (2):100-113. 2009. 
SANTIAGO, T.M.O.; Rezende, J.L.P.; Borges, L.A.C.; Borges, A.F.; Santos, A.A. A eficácia da avaliação de impactos ambientais no Brasil. Revista Ibero-Americana de Ciências Ambientais, $6(2): 37-51.2015$.

SC - Santa Catarina. Secretaria de Estado de Infraestrutura e Mobilidade. Mapa Rodoviário Estadual. Arquivos shapefile. Sem escala. 2020.

TROJAN, M. Relatório de Execução do Plano de Remediação da Área Degradada da Antiga Usina de Asfalto. 35p. 2005. 